\title{
PHOSPHATE REMOVAL FROM REAL WASTEWATER USING MAGHEMITE BEADS
}

\author{
Marjana Simonič \\ * University of Maribor, Faculty of Chemistry and Chemical Engineering, Maribor, Slovenia \\ corresponding author: Marjana Simonič, e-mail: marjana.simonic@um.si
}

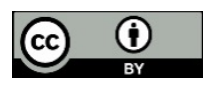

This work is licensed under a

Creative Commons Attribution 4.0

$\underline{\text { International License }}$
Original scientific paper

Received: February $6^{\text {th }}, 2019$

Accepted: April 15 th 2019

HAE-1906

https://doi.org/10.33765/thate.9.2.1

\begin{abstract}
The present study aimed at research of phosphate adsorption onto poly(vinyl-alcohol) PVA alginate beads in comparison with maghemite modified beads from wastewater. The characterisation of material was performed by Fourier transform infrared spectroscopy (FTIR) and X-ray diffraction. The influence of $\mathrm{pH}$ and the quantity of maghemite nanoparticle was studied.

The results of phosphate adsorption onto PVA-alginate beads showed $45 \%$ of initial $\mathrm{PO}_{4}{ }^{3-}$ concentration removal from wastewater while the maghemite PVA-alginate beads showed better adsorption activity at $70 \%$ of initial $\mathrm{PO}_{4}{ }^{3-}$ removal. The optimal dose was determined at $0.9 \mathrm{~g}$ of PVA-M beads (containing $0.01 \mathrm{~g}$ maghemite) added to the $50 \mathrm{~mL}$ wastewater. The efficiency of phosphate removal from wastewater was relatively low due to content of coexistent anions, including $\mathrm{SO}_{4}{ }^{2-}, \mathrm{CO}_{3}{ }^{2-}, \mathrm{NO}_{3}{ }^{-}$and $\mathrm{Cl}^{-}$, which compete with phosphate for the binding sites, hindering $\mathrm{PO}_{4}{ }^{3-}$ to form inner sphere complexes.
\end{abstract}

Keywords: maghemite beads, phosphate removal, wastewater

\section{INTRODUCTION}

Orthophosphate $\mathrm{PO}_{4}{ }^{3-}$ represents an important macronutrient in aquatic environment, but overgrowth of algae causes dissolved oxygen depletion. Sorption processes show potential for phosphate removal from wastewater by offering advantages, such as low sludge production, simple operation, etc. [1].

Different natural immobilisation media have been used for biomatrix immobilisation, nevertheless alginate is still one of the most frequently used carriers [2]. Sodium alginate is one of the most studied natural polymers for metal ions removal [3]. Alginate is known to be fragile and cannot be recycled [1]. Immobilisation of one polymer to another is a common practice in production of durable beads [4]. Maghemite nanoparticles are incorporated with alginate and poly(vinylalcohol) PVA to enhance the ability of bead as a biosorbent. The immobilization of maghemite is simple and cost effective. PVA$M$-beads were used for efficient removal of cesium from wastewater [5]. 
The synthesis of nanostructure magnetic materials has become a particularly important area of research because of its potential applications in the field of water remediation [6]. Further studies are required to compare the $\mathrm{PO}_{4}{ }^{3-}$ removal by using iron oxides [6]. It was reported that $\mathrm{Fe}_{3} \mathrm{O}_{4}$ has the potential to remove toxic elements such as arsenic from water [7]. Authors also claim that it is still rare to find the investigation of removal/recovery of phosphate by using $\mathrm{Fe}_{3} \mathrm{O}_{4}$. Therefore, the present study aimed at efficient adsorption of phosphate from wastewater onto PVA alginate beads in comparison with maghemite modified beads, which is the novelty of present study. The aim of the research was to study the influence of other compounds in wastewater on phosphate removal as well as the influence of concentration of maghemite in beads. Iron oxide based nanoparticles are purposely incorporated with alginate and PVA to enhance the efficiency of pollutant removal [8].

\section{EXPERIMENTAL}

\section{Preparation of maghemite nanostructures}

Nanoparticles were prepared by a topotactic transformation of a $\gamma-\mathrm{FeO}(\mathrm{OH})$. Firstly, the 2 $\mathrm{mM} \mathrm{FeCl} 2 \cdot 4 \mathrm{H}_{2} \mathrm{O}$ solution was prepared in 100 $\mathrm{mL}$ of de-oxygenated milli-Q water. The solution was exposed to $\operatorname{Ar}(300 \mathrm{~mL} / \mathrm{min})$ for $30 \mathrm{~min} .2 \mathrm{~mL}$ of pyridine was poured into the solution and again exposed. After $1 \mathrm{~h}$ the oxygen gas flew at $300 \mathrm{~mL} / \mathrm{min}$ through the reaction mixture for $15 \mathrm{~min}$, followed by oxygen flow of $50 \mathrm{~mL} / \mathrm{min}$ (for $3 \mathrm{~h}$ ). The solid to $\gamma-\mathrm{FeO}(\mathrm{OH})$ product was centrifuged and washed several times with distilled water. The dehydroxilation of the $\gamma-\mathrm{FeO}(\mathrm{OH})$ was performed in a furnace at $280{ }^{\circ} \mathrm{C}$ for $1 \mathrm{~h}$ in air. In Figure 1 maghemite nanostructure in a weigh boat is seen.

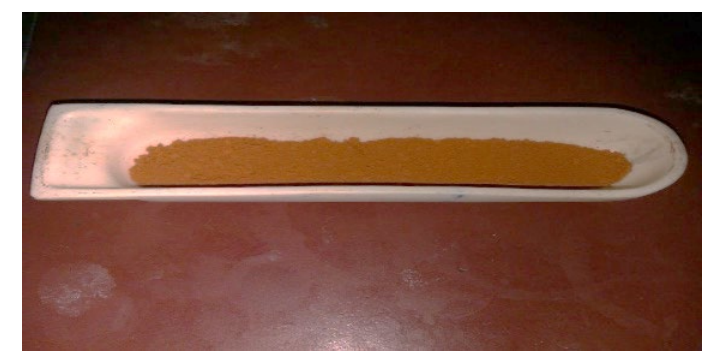

Figure 1. Maghemite nanostructure

\section{Preparation of PVA beads}

PVA solution was prepared by dissolving $24 \mathrm{~g}$ of PVA in $200 \mathrm{~mL}$ flask in Millipore water at $120^{\circ} \mathrm{C}$ for $3 \mathrm{~h}$. Separately alginate solution was prepared by dissolving $2 \mathrm{~g}$ of alginate in $40 \mathrm{~mL}$ water. Both solutions were poured together. White beads were formed by using plastic transfer pipette.

The same procedure was used for preparing PVA alginate beads with maghemite (PVA-Mbeads). Into the prepared solution $0.2 \mathrm{~g}$ of maghemite was added. Beads were kept in the solution containing $2 \% \mathrm{CaCl}_{2}$ and $6 \%$ boric acid for $24 \mathrm{~h}$. Then beads were rinsed and kept in Millipore water as seen from Figure 2.

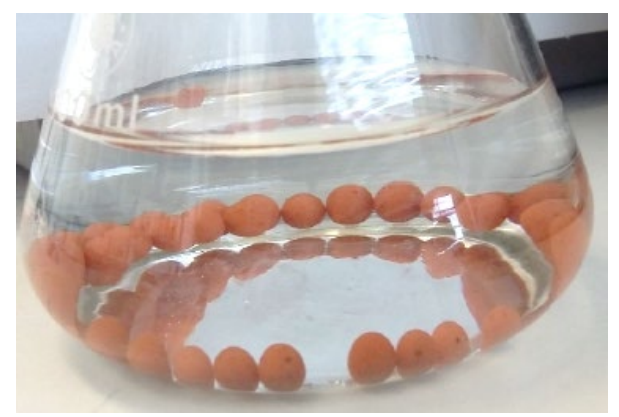

Figure 2. Maghemite PVA-alginate beads in Millipore water

\section{Material characterisation}

The samples were characterized by a Fourier transform infrared spectroscopy (FTIR). Spectrophotometer IRAffinity-1 (Shimadzu) was used. For X-ray diffraction (XRD) a Bruker D5005 diffractometer (Siemens) was used $\left(\mathrm{Cu}-\mathrm{K} \alpha\right.$ radiation with $2 \theta$ from $20^{\circ}$ to $70^{\circ}$ at a scan rate of $2 \%$ minute). 


\section{Adsorption in real wastewater samples}

The real wastewater samples were taken from the inflow into the local wastewater treatment plant. The COD (chemical oxygen demand) was determined at $760 \mathrm{mg} / \mathrm{L}$, BOD (biochemical oxygen demand) at $310 \mathrm{mg} / \mathrm{L}$ and TSS (total suspended solids) at $325 \mathrm{mg} / \mathrm{L}$. Representative samples were taken after $24 \mathrm{~h}$ of sampling. The initial phosphate concentration was measured and adsorption on PVA beads was performed.

The solution $\mathrm{pH}$ condition was adjusted to 7.0 with $0.1 \mathrm{M}$ of $\mathrm{HCl}$ using a portable $\mathrm{pH}$-meter (WTW Multi 3410, Germany). The reaction vessels were then homogeneously shaken in an orbit shaking incubator at $250 \mathrm{rpm}$ with controlled temperature at $20{ }^{\circ} \mathrm{C}$ for different time periods of 20, 40, 60 and $240 \mathrm{~min}$ and the analyses on phosphate were performed.

The samples were immediately filtered using a filter with an opening of $0.45 \mu \mathrm{m}$; the phosphate concentrations in the filtrates were then analysed using an Agilent Spectrophotometer. Removal efficiency of phosphate removal $(E)$ is calculated following equation (1):

$$
E=\left(c_{\mathrm{i}}-c_{\mathrm{f}}\right) / c_{\mathrm{f}} \cdot 100
$$

where $c_{\mathrm{i}}$ is initial concentration and $c_{\mathrm{f}}$ is final phosphate concentration.

\section{RESULTS AND DISCUSSION}

\section{The results of material characterisation}

The FTIR spectrum of maghemite nanostructure is illustrated in Figure 3. A characteristic adsorption band at $559 \mathrm{~cm}^{-1}$, which can be attributed to the $\mathrm{Fe}-\mathrm{O}$ bond of maghemite, was observed.

The XRD spectrum in Figure 4 confirmed the formation of maghemite. The XRD graph showed good crystallinity, with sharp peaks. The patterns can also be seen at 30,35 and 57 on 2-Theta-Scale which is typical for maghemite structure [9].

PVA-M-beads contained $0.1 \mathrm{~g}$ maghemite $/ 100$ g PVA- alginate. BET, pore radius and pore volume were determined at $9.38 \mathrm{~m}^{2} / \mathrm{g}, 1.4$ $\mathrm{mm}$ and $7.42 \cdot 10^{-2} \mathrm{~cm}^{3} / \mathrm{g}$, respectively. The removal efficiencies of phosphate removal achieved with PVA beads was $97.9 \%$ and PVA-M-beads $98.5 \%$, respectively are reported elsewhere [10].

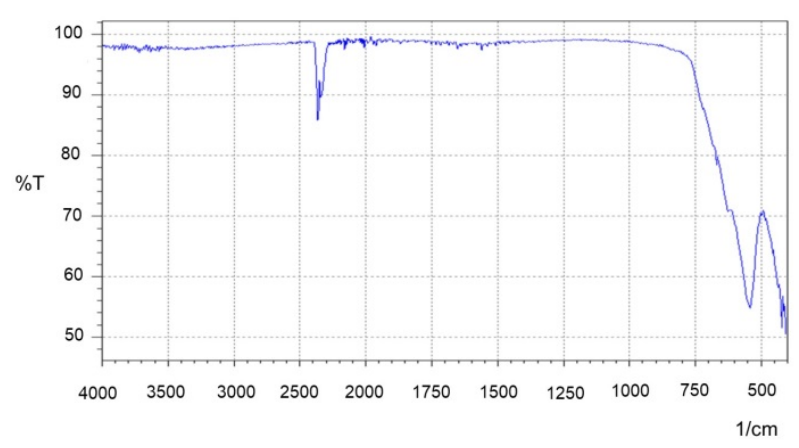

Figure 3. FTIR spectrum of maghemite

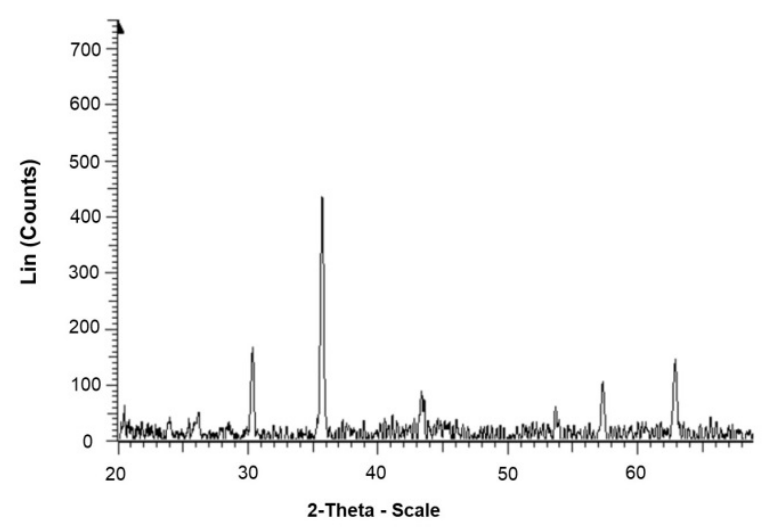

Figure 4. The XRD pattern of maghemite

\section{The results of experiments using real wastewater}

Samples of real wastewater were taken from local wastewater treatment plant. Initial concentration was $5 \mathrm{mg} / \mathrm{L} \mathrm{PO}_{4}{ }^{3-}$. The optimum dosage of PVA was determined at $0.45 \mathrm{~g}$ beads in $50 \mathrm{~mL}$ or $0.005 \mathrm{~g}$ maghemite per 0.45 g PVA-M-beads in $50 \mathrm{~mL}$ were added.

The efficiency was determined with PVA and PVA-M-beads. The results are presented in Table 1. After $240 \mathrm{~min}$ the efficiency of $\mathrm{PO}_{4}{ }^{3-}$ 
removal increased. However, the results are much worse compared to those with model solutions. At the same amount of beads the removal percentage was lower. PVA-M-beads were more efficient then PVA beads which is in accordance with model solution results [10].

Table 1. Comparison of removal efficiency with PVA and PVA-M-beads

\begin{tabular}{|c|c|c|}
\hline$t, \min$ & $E(\mathrm{PVA}-\mathrm{M}), \%$ & $E(\mathrm{PVA}), \%$ \\
\hline 20 & 30.4 & 23.5 \\
\hline 40 & 32.5 & 31.5 \\
\hline 60 & 35.5 & 33.5 \\
\hline 240 & 43.8 & 36.7 \\
\hline
\end{tabular}

The maximum allowed concentration in municipal wastewater is determined at $2 \mathrm{mg} / \mathrm{L}$ $\mathrm{PO}_{4}{ }^{3-}$ [10]. It was calculated that the concentration of phosphates remained above statutory value. The exchange of $\mathrm{OH}^{-}$ions and phosphate in wastewater was low due to presence of other negative ions which have higher affinity to $\mathrm{OH}^{-}$ions than $\mathrm{PO}_{4}{ }^{3-}$ [11]. Municipal and industrial wastewaters always contain coexistent anions, including $\mathrm{SO}_{4}{ }^{2-}$, $\mathrm{CO}_{3}{ }^{2-}, \mathrm{NO}_{3}{ }^{-}, \mathrm{F}^{-}, \mathrm{Br}^{-}, \mathrm{I}^{-}$and $\mathrm{Cl}^{-}$, which may compete with phosphate for the binding sites [5]. The decrease in $\mathrm{PO}_{4}{ }^{3-}$ adsorption with an increase in $\mathrm{pH}$ might be mainly due to electrostatic attraction. Strong competition occurs between $\mathrm{PO}_{4}{ }^{3-}$ species $\left(\mathrm{H}_{2} \mathrm{PO}_{4}{ }^{-}\right.$, $\mathrm{HPO}_{4}{ }^{2-}$, and $\left.\mathrm{PO}_{4}{ }^{3-}\right)$ and hydroxyl $\left(\mathrm{OH}^{-}\right)$ions at higher $\mathrm{pH}$, creating strong repulsions between phosphate and hydroxyl ions that reduces adsorption [1]. The introduction of $\mathrm{HCO}_{3}{ }^{-}$also hinders phosphate adsorption. In the next step $\mathrm{pH}$ was measured in order to compare this value with the optimum one. The results are presented in Table 2 . It can be seen that the initial $\mathrm{pH}$ value was 7.87 and it is alkaline. $\mathrm{pH}$ value was measured every 10 min. Small $\mathrm{pH}$ value increase was noticed, but it stabilised after $40 \mathrm{~min}$. The presence of $\mathrm{CO}_{3}{ }^{2-}$ caused the $\mathrm{pH}$ to rise, resulting in decrease of $\mathrm{PO}_{4}{ }^{3-}$ removal due to repulsions between phosphate and hydroxyl ions [5].

The experiments were done at different $\mathrm{pH}$ values 5, 6 and 7. Differences in $\mathrm{PO}_{4}{ }^{3-}$ concentrations at $240 \mathrm{~min}$ were negligible in wastewater at all three $\mathrm{pH}$ values as seen from Figure 5. The final concentration was measured at $1.5 \mathrm{mg} / \mathrm{L} \mathrm{PO}_{4}{ }^{3-}$.

Table 2. $\mathrm{pH}$ value in municipal water

\begin{tabular}{|c|c|c|}
\hline$t, \min$ & $\mathrm{pH}(\mathrm{PVA}-\mathrm{M})$ & $\mathrm{pH}(\mathrm{PVA})$ \\
\hline 0 & 7.87 & 7.87 \\
\hline 20 & 8.10 & 7.99 \\
\hline 40 & 8.14 & 8.03 \\
\hline 60 & 8.18 & 8.06 \\
\hline 240 & 8.18 & 8.06 \\
\hline
\end{tabular}

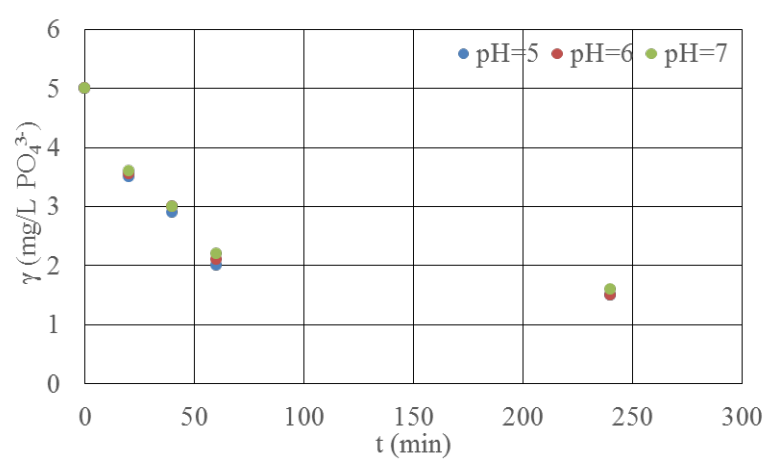

Figure 5. Phosphate concentrations during adsorption on PVA-M-beads in wastewater at different $\mathrm{pH}$

Due to the lowest $\mathrm{HCl}$ consumption needed for $\mathrm{pH}$ adjustment, the optimum $\mathrm{pH}$ was determined at 7 . The wastewater $\mathrm{pH}$ was adjusted to 7 and the experiments were done again with the same mass of beads $0.45 \mathrm{~g}$ in 50 $\mathrm{mL}$ wastewater. The phosphate concentration was measured after 20, 40, 60 and $240 \mathrm{~min}$. The results are seen from Figure 6.

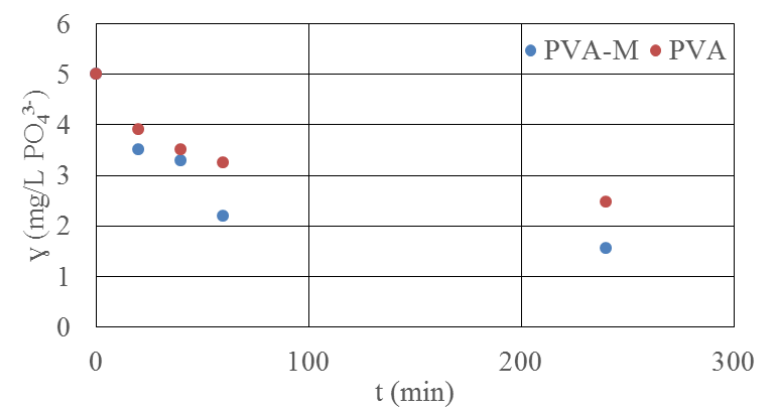

Figure 6. Phosphate concentrations in wastewater after treatment at $\mathrm{pH}=7$

From Figure 6 it is seen that the concentration of $\mathrm{PO}_{4}{ }^{3-}$ decreased from $5 \mathrm{mg} / \mathrm{L}$ below $2 \mathrm{mg} / \mathrm{l}$ after $240 \mathrm{~min}$ and the concentration is very 
close to $2 \mathrm{mg} / \mathrm{L}$ after $60 \mathrm{~min}$. At shorter contact times $\mathrm{PO}_{4}{ }^{3-}$ is not removed sufficiently.

The larger decrease in $\mathrm{PO}_{4}{ }^{3-}$ adsorption onto maghemite particles could be reduced due to inner-sphere complexation between anions and surface groups [11].

PVA- beads gave worse results and the concentration did not decrease below statutory value. Nanosized material, such as PVA-Mbeads always showed better contact between adsorbents with phosphate than PVA- beads in accordance with another study [12]. It could be concluded that alginate beads modified with maghemite are promising for the application of phosphate removal in real systems while PVAbeads did not give satisfactory results.

Another experiment was conducted with the doubled mass $0.9 \mathrm{~g}$ of PVA-M beads (containing $0.01 \mathrm{~g}$ maghemite) added to the 50 $\mathrm{mL}$ aliquot of the same sample of real wastewater. The adsorption of $\mathrm{PO}_{4}{ }^{3-}$ did not change significantly. The concentration decreased from $5 \mathrm{mg} / \mathrm{L}$ to $1.5 \mathrm{mg} / \mathrm{L} \mathrm{PO}_{4}{ }^{3-}$ after 240 min which represents $70 \% \mathrm{PO}_{4}{ }^{3-}$ removal. No significant changes in removal efficiencies were noticed compared with lower beads amount.

The adsorbent surface contains a fixed number of binding sites, many of which remain occupied in wastewater with other anions, such as $\mathrm{SO}_{4}{ }^{2-}$, which form outer complexes with beads [12]. Due to repulsion between $\mathrm{SO}_{4}{ }^{2-}$ and $\mathrm{PO}_{4}{ }^{3-}$, the concentrations of $\mathrm{PO}_{4}{ }^{3-}$ did not decrease as much as in model solution, where inner sphere complexes were formed during $\mathrm{PO}_{4}{ }^{3-}$ elimination in accordance with literature [1].

\section{CONCLUSION}

The phosphate adsorption onto poly(vinylalcohol) PVA alginate beads from wastewater in comparison with maghemite modified PVA alginate beads was evaluated. The influence of
$\mathrm{pH}$ and the quantity of maghemite nanoparticle in PVA alginate beads was studied.

In the real wastewater samples, the $\mathrm{pH}$ value was very important, while at neutral $\mathrm{pH}$ the phosphates could be removed below statutory value but only with maghemite modified beads. The removal efficiency was $70 \%$ of initial $\mathrm{PO}_{4}{ }^{3-}$ concentration. The efficiency of phosphate removal from wastewater was relatively low due to content of coexistent anions, including $\mathrm{SO}_{4}{ }^{2-}, \mathrm{NO}_{3}{ }^{-}$and $\mathrm{Cl}^{-}$, which compete with phosphate for the binding sites.

\section{REFERENCES}

[1] Z. Ajmal, A. Muhmood, M. Usman, S. Kizito, X. Lu, R. Dong, S. Wu, Phosphate removal from aqueous soultion using iron oxides: Adsorption, desorption and regeneration characteristics, Journal of Colloid and Interface Science 538(2018), 145-155.

[2] K. Jung, T.U. Jeong, J.W. Choi, K.H. Ahn, S.H. Lee, Adsorption of phosphate from aqueous solution using electrochemically modified biochar calcium-alginate beads: Batch and fixedbed column performance, Bioresource Technology 244(2017), 23-32.

[3] N. Akhtar, A. Saeed, M. Iqbal, Chlorella sorokiniana immobilized on the biomatrix of vegetable sponge of Luffa cylindrica: a new system to remove cadmium from contaminated aqueous medium, Bioresource Technology 88(2003), 163-165.

[4] B. Hui, Y. Zhang, L. Ye, Preparation of PVA hydrogel beads and adsorption mechanism for advanced phosphate removal, Chemical Engineering Journal 235(2014), 207- 214.

[5] Z. Majidnia, A. Idris, Evaluation of cesium removal from radioactive waste water usnig maghemite PVA-alginate beads, Chemical Engineering Journal 262(2015), 372- 382.

[6] L Ruiting, C. Lina, W. Hinze, S. Yanming, A. Hamidreza, Review of 
metal (hydr)oxide and other adsorptive materials for phosphate removal from water, Journal of Environtal Chemical Engineering 6(2018) 4, 5269-5286.

[7] Y.J. Tu, C.F. You, C.K. Chang, M.H. Chen, Application of magnetic nanoparticles for phosphorus removal/recovery in aqueous solution, Journal of the Taiwan Institute of Chemical Engineers 46(2015), 148-154.

[8] Z. Majidnia, A. Idris, Photocatalytic reduction of iodine in radioactive waste water using maghemite and titania nanoparticles in PVA-alginate beads, Journal of the Taiwan Institute of Chemical Engineers 54(2015), 137-144.

[9] A. Tiya Djowe, E. Acayanka, R.G. Lontio Nkouongfo, S. Laminsi, E.M Gaigneaux, Enhanced discolouration of Methyl Violet 10B in a gliding arc plasma reactor by the maghemite nanoparticles used as heterogeneous catalyst, Journal of Environmental Chemical Engineering 3(2015) 2, 953960.

[10] N. Ribič, Uporaba alginatnih nosilcev za odstranjevanje onesnažil iz vode (en: The usage of alginate beads for pollutant removal from water), Graduate thesis, University of Maribor, Maribor, Slovenia, 2016.

[11] D.N.H. Tran, S. Kabiri, L. Wang, D. Losic, Engineered graphene-nanoparticle aerogel composites for efficient removal of phosphate from water, Journal of Material Chemistry A 3(2015), 68446852.

[12] B. Pan, F. Han, G. Nie, B. Wu, K. He, L. $\mathrm{Lu}$, New strategy to enhance phosphate removal from water by hydrous manganese oxide, Environmental Science \& Technology 48(2014) 9, 5101-5107.

\section{Acknowledgements}

The author thanks the program Process System Engineering and Sustainable Development, ID
P2-0032, which was financially supported by the Slovenian Research Agency. 